\title{
Immediate implantation after extraction laser assisted protocol
}

\author{
Protocol de implantare imediată postextracţională laser asistată
}

\author{
Ionuț Daniel Mihai'1,2, Roxana Mihai ${ }^{2}$, Raluca Monica Comăneanu' ${ }^{1}$ Doina Lucia Ghergic ${ }^{1}$ \\ ${ }^{1}$ Facultatea de Medicină Dentară, Universitatea „Titu Maiorescu“, Bucureşti, România \\ ${ }^{2}$ SELARL de chirurgiens dentistes Daniel et Roxana Mihai, Châtellerault, Franţa
}

\begin{abstract}
Objectives. We have developed and applied an assisted laser immediate implantation protocol to accelerate postoperative healing and reduce the incidence of inflammatory or infectious complications. Material and method. After rigorous selection of patients who were candidates for immediate implantation, we applied to them an operator protocol that included the use of surgical guides, local assisted laser decontamination, atraumatic dental extraction with piezosurgery, immediate insertion of dental implants and postoperative biostim-ulation with laser.

Results and discussion. We have exemplified the previously described operator protocol for a 58year, non-smoker, and clinically healthy patient. Digital planning of treatment and guided insertion of implants has in-creased the precision of the act. The use of the piezosurgery for the dental extraction had a major role in preserv-ing the bone of the patient. Also, laser decontamination and biostimulation reduced the incidence of postoperative complications and discomfort and hurried the wound healing.

Conclusions. The patient had no complications of inflammatory or infectious in any postoperative control. The limits of the procedure are due to the increased cost of the necessary equipment and to the possible undesired effects of inappropriate laser irradiation carried out by inadequately trained specialists.
\end{abstract}

Keywords: immediate implantation, laser, piezosurgery, surgical guide, biostimulation

\section{REZUMAT}

Obiective. Am elaborat şi aplicat un protocol de implantare imediată laser asistată cu scopul de a grăbi vindecarea postoperatorie şi de a reduce incidenţa complicaţiilor inflamatorii sau infecţioase.

Material şi metodă. După selectarea riguroasă a pacienţilor candidaţi la implantarea imediată, am aplicat acestora un protocol operator ce a cuprins utilizarea ghidurilor chirurgicale, decontaminarea locală laser asistată, extracţia dentară atraumatică cu ajutorul piezotomului, inserarea imediată postextracţională a implantelor dentare şi biostimularea laser postoperatorie.

Rezultate şi discuţii. Am exemplificat protocolul operator descris anterior în cazul unei paciente de 58 ani, nefumătoare şi clinic sănătoasă. Planificarea digitală a tratamentului şi inserarea ghidată a implantelor a spo-rit precizia actului operator. Utilizarea piezotomului pentru efectuarea extracţiei dentare a avut un rol major în conservarea osului pacientului. De asemenea, decontaminarea şi biostimularea laser au redus incidenţa complicaţiilor şi disconfortului postoperator şi au grăbit vindecarea plăgii.

Concluzii. Pacienta nu a prezentat complicaţii de natură inflamatorie sau infecţioasă la nici un control postoperator. Limitele aplicabilităţii procedurii sunt date de costul crescut al aparaturii necesare şi de posibilele efecte nedorite ale iradierii laser impropriu efectuate de către specialişti insuficient pregătiţi în domeniu.

Cuvinte cheie: implantare imediată, laser, piezochirurgie, ghid chirurgical, biostimulare

\section{INTRODUCERE}

Exigențele tot mai crescânde ale pacienților au dus la dezvoltarea şi utilizarea din ce în ce mai frec- ventă a protocoalelor de implantare imediată postextracțională.

Resorbția osoasă postextracțională poate interesa în primii 2 ani după pierderea dintelui între 40 şi 
$60 \%$ din volumul osului alveolar maxilar anterior. Acest aspect poate modifica un plan de tratament implanto-protetic şi poate obliga medicul dentist să recurgă la metode ajutătoare de augumentare osoasă (1).

Unii autori (2) au propus anumite criterii de selecție a pacienților candidați pentru procedurile de implantare imediată, excluzându-i pe aceia care prezentau infecții acute sau parodontite netratate, pentru a mări rata de succes a intervenției.

\section{MATERIAL ŞI METODĂ}

La pacienţii clinic sănătoşi sau cu afecțiuni generale compensate sub tratament medicamentos am aplicat un protocol operator de implantare imediată postextracțională laser asistată, ce cuprinde în fazele preliminare, pe lângă examinarea clinică şi paraclinică inițială (model de studiu, CBCT), planificarea tratamentului cu SimPlant ${ }^{\mathbb{R}}$ şi confecționarea ghidului chirurgical.

Anterior efectuării extracției dentare atraumatice cu ajutorul piezotomului, am aplicat un protocol de decontaminare locală parodontală laser asistată ce cuprinde detartraj supra şi subgingival sub irigație cu ser fiziologic şi metronidazol, debridare parodontală manuală şi mecanică cu laser ErCr, airflow, decontaminare laser diodă şi $\mathrm{H}_{2} \mathrm{O}_{2}$, biostimulare cu laser diodă pentru regenerarea parodontală.

După efectuarea extracției dentare, am practicat o decontaminare osoasă ce a cuprins chiuretajul minuțios al eventualelor leziuni periapicale pentru a elimina țesutul de granulație din alveolă şi de a evita aparitia complicațiilor infectioase postoperatorii, urmat de lavaj în alveolă cu antibiotic (gentamicină) şi ser fiziologic, precum şi decontaminare laser diodă şi $\mathrm{H}_{2} \mathrm{O}_{2}$.

În aceeaşi şedință, am efectuat prepararea ghidată a neoalveolei pentru implant şi prepararea osului adiacent cu laserul ErCr, iar după inserarea implantului am realizat biostimularea cu laserul diodă pentru îmbunătățirea cicatrizării postoperatorii. Protezarea provizorie efectuată în primele 48 ore după intervenție a fost urmată de protezarea definitivă la 2 luni şi jumătate de la implantarea imediată.

\section{REZULTATE OBŢINUTE}

Vă prezentăm cazul unei paciente, în vârstă de 58 de ani, clinic sănătoasă, nefumătoare, care s-a prezentat în cabinetul de medică dentară solicitând reabilitarea orală a arcadei inferioare.

În urma efectuării examenului clinic şi paraclinic (Fig. 1), am propus pacientei extracția dinților irecuperabili $(37,44,46,47)$ şi protezarea edentațiilor cu ajutorul unor restaurări protetice fixe cu sprijin implantar.

De comun acord cu pacienta, am hotărât inserarea imediată a 5 implante Zimmer TSV, două pe hemiarcada stângă şi trei pe hemiarcada dreaptă. Pentru completarea spațiilor interalveolare restante, am propus augmentarea cu xenogrefă bovină (Bio-Oss).

Pentru a spori precizia implantării, am confecționat preoperator un ghid chirurgical. Conform protocolului, am efectuat decontaminarea parodontală locală laser asistată şi am realizat într-o primă etapă chirurgicală extracția atraumatică a lui 37.

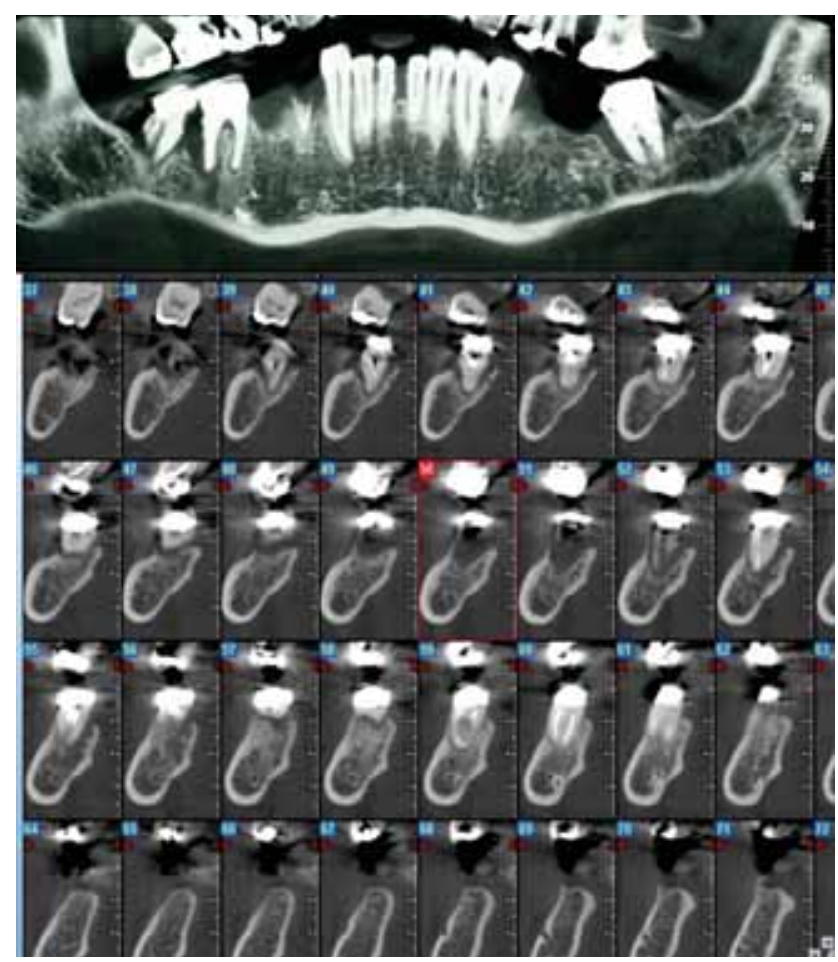

FIGURA 1. Examen imagistic inițial

Pentru buna evidențiere a câmpului operator, am realizat un lambou muco-periostal şi am efectuat un chiuretaj minuţios al alveolei, urmat de lavaj cu gentamicină şi ser fiziologic, apoi de decontaminare laser. După verificarea paralelismului, am inserat ghidat două implante la un torque de $45 \mathrm{Nm}$, apoi am efectuat sutura mucoperiostului şi biostimularea locală cu laserul diodă (Fig. 2).

În a doua etapă chirurgicală s-a realizat extracția lui 44, 46 şi 47 cu chiuretaj alveolar, lavaj antibiotic 
şi decontaminare laser conform protocolului operator; pentru forajul neoalveolelor, am folosit ghidul chirurgical pentru a poziționa axele de foraj în perimetrul ocluzal al viitoarelor coroane şi am inserat 3 implante cu adiție osoasă de Bio-Oss, urmată de sutură cu monofilament Prolene 4/0 şi biostimulare locală laser asistată (Fig. 3).

Protezarea provizorie s-a realizat la 48 de ore, iar cea definitivă la 2 luni şi jumătate.

\section{DISCUŢII}

Protocolul propus, aplicabil în cazurile de implantare imediată postextracțională, cuprinde etape de decontaminare şi biostimulare laser, cu rol în grăbirea vindecării postextracționale şi postimplantare.

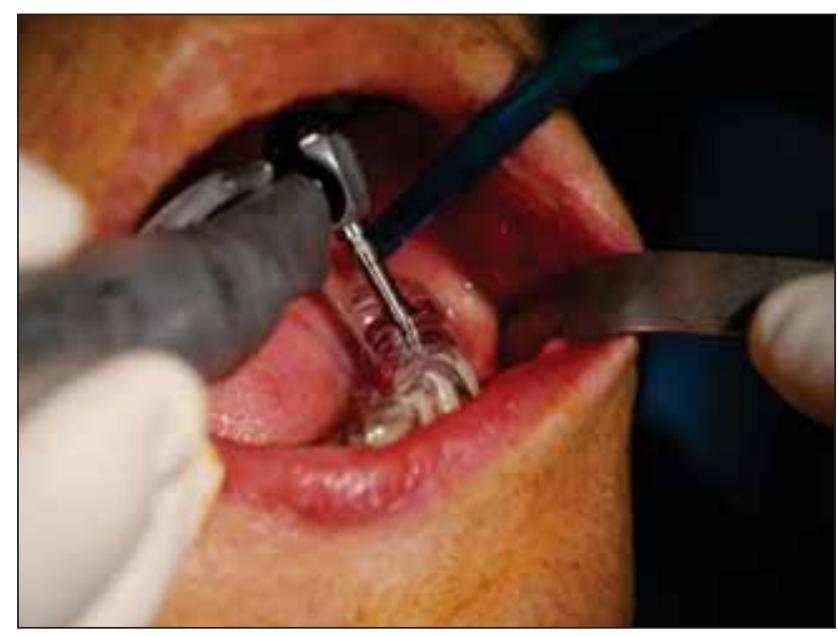

a

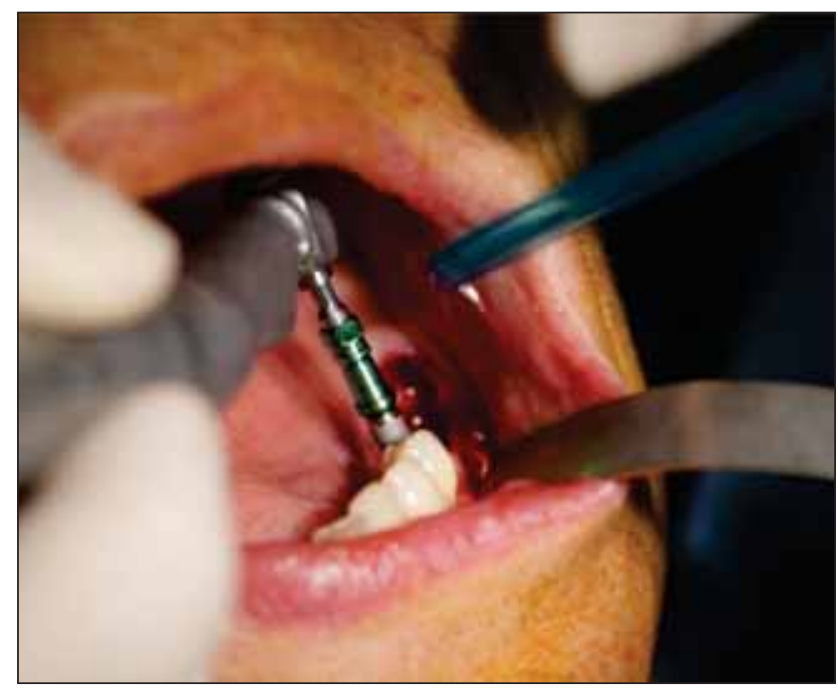

c

FIGURA 2. (a) Forajul neoalveolelor din cadranul 3 prin ghidul chirurgical; (b) Verificarea paralelismului între axul de inserție implantară şi dinții restanți; (c) Inserarea primului implant la $45 \mathrm{nM}$; (d) Biostimularea sitului postoperator prin procesul fotochimic cu ajutorul laserului diodă
Tehnicile radiologice convenționale au fost înlocuite în protocolul nostru de CT şi CBCT pentru a oferi o cantitate mare de informații despre viitorul situs implantar $(3,4)$, precum cantitatea şi calitatea osoasă, prezența şi localizarea structurilor anatomice relevante şi a eventualelor aspecte patologice, precum şi relația lor cu viitoarea reabilitare (5).

Planificarea digitală a tratamentului cu posibilitatea inserării ghidate reprezintă o contribuție importantă la exactitatea tratamentului şi evitarea complicațiilor (6). Poziţionarea precisă şi previzibilă a implantului folosind ghidul chirurgical este foarte importantă pentru rezultatul final estetic şi funcțional al protezei (7). Aceasta implică o planificare inversă, ce presupune inițial planificarea poziției ideale a restaurării protetice pe arcadă, urmată de planificarea implantului şi plasarea sa în locaţia corespunzătoare (8).

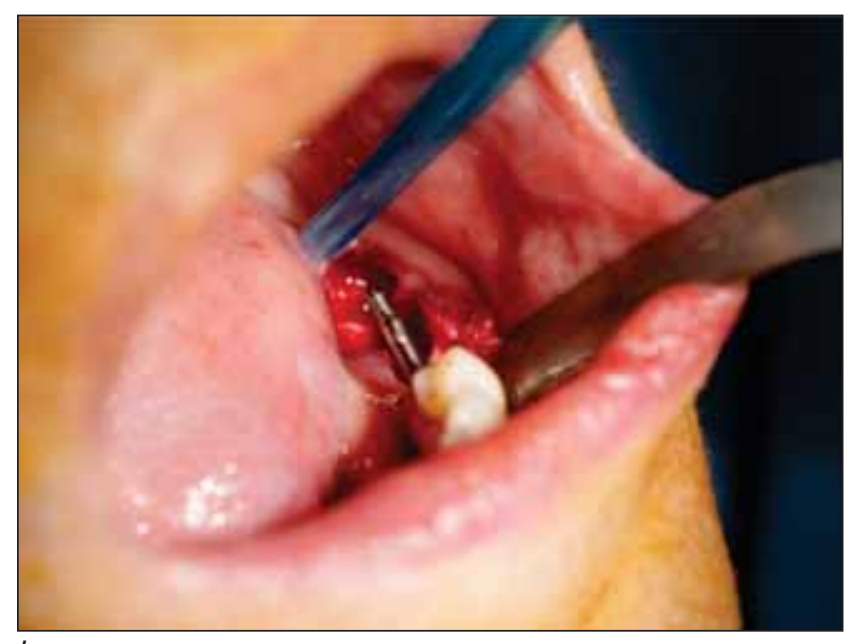

$b$

$d$

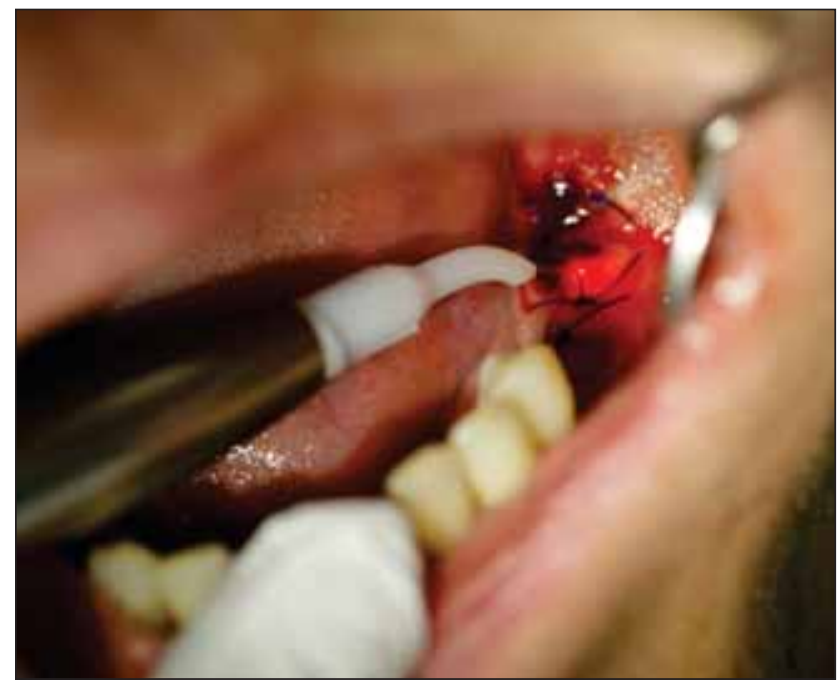




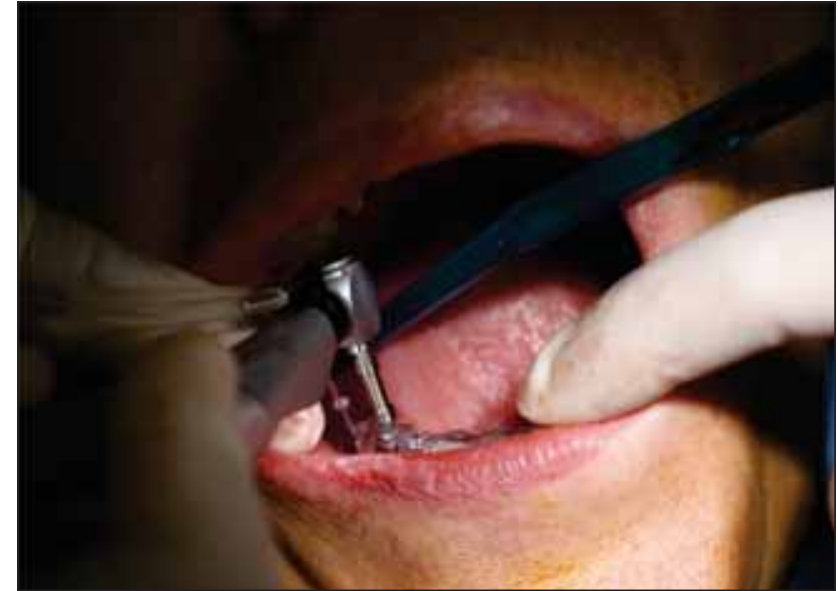

a

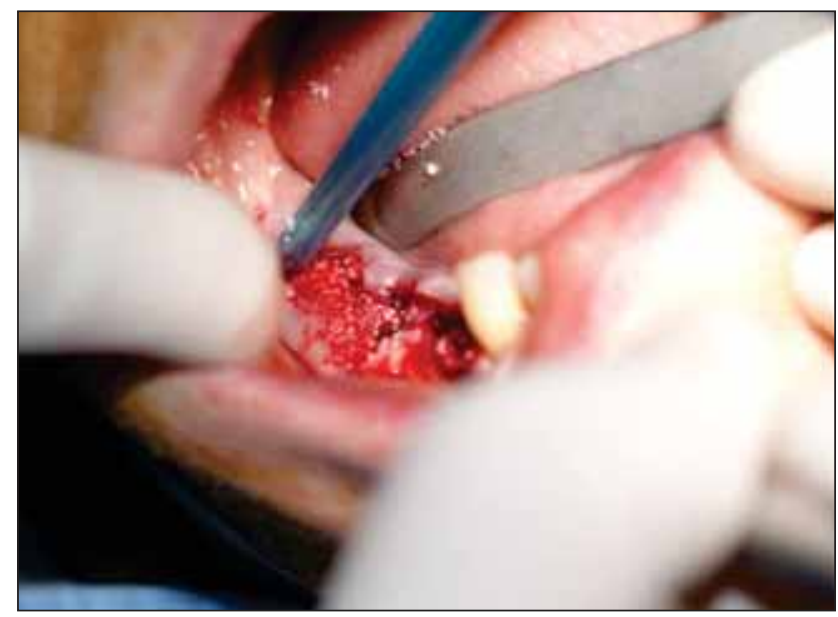

$c$

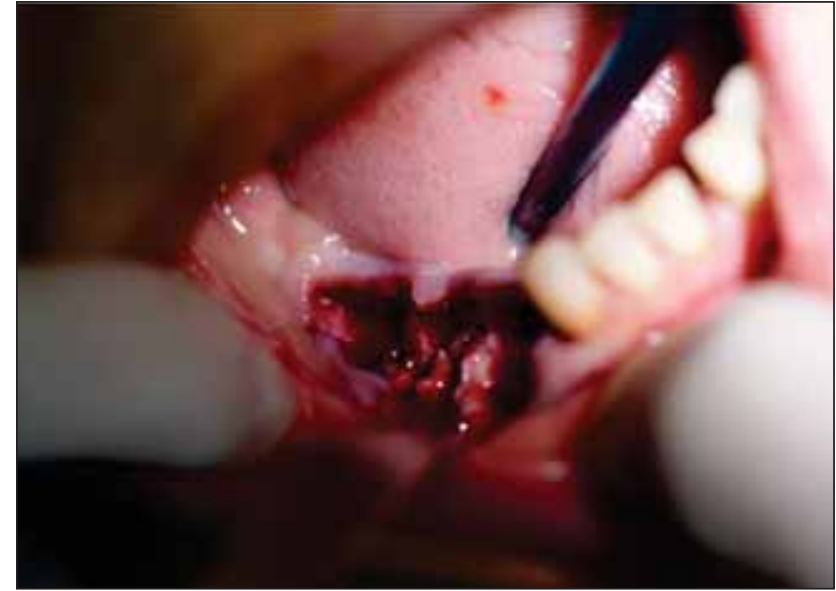

$b$

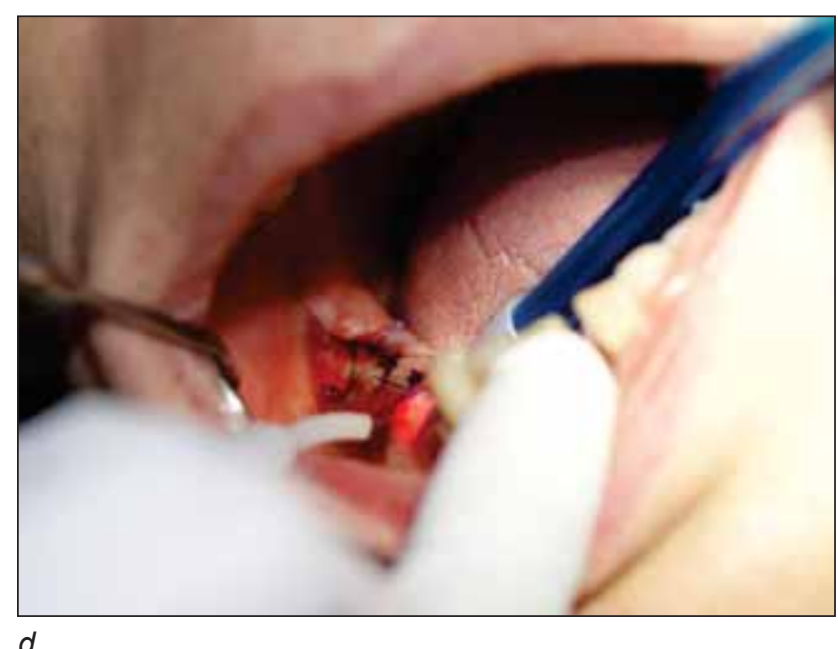

FIGURA 3. (a) Plasarea ghidului chirurgical şi forajul neoalveolelor în cadranul 4 cu respectarea axelor stabilite în urma planificării; (b) Inserarea implantelor în pozițiile 46 şi 47; (c) Adiția osoasă periimplantară cu Bio-Oss amestecat cu ser fiziologic şi Metronidazol; (d) Biostimularea sitului postoperator prin procesul fotochimic cu ajutorul laserului diodă

Introducerea laserilor reprezintă un punct de cotitură important în stomatologie şi, în prezent, o multitudine de proceduri sunt efectuate utilizând diferite tipuri de laseri (9), încorporaţi în practica zilnică (10).

În medicina dentară există două tipuri de laseri care se utilizează: laseri cu aplicabilitate doar pe țesurile moi şi laseri care se pot aplica atât pe țesuturile moi, cât şi pe țesuturile dure. Pentru ca laserul să interacționeze cu un țesut specific este necesar ca în țesutul respectiv să existe o substanță numită cromofor care să absoarbă fasciculul laser (9). Pentru țesuturile moi, cromoforii sunt melanina şi hemoglobina, iar pentru țesuturile dure cromoforii sunt apa şi hidroxiapatita $(11,12)$.

Primele lasere aprobate în stomatologie de US Food and Drug Administration au fost Nd:YAG şi laserul diodă, acceptate doar pentru procedurile parodontale ce implică țesuturi moi. Laserii cu aplica- ție în chirurgia țesuturilor dure sunt Er(erbium):YAG şi ErCr (erbium, chromium): YSGG (yttrium, scandium, gallium, garnet (13).

În prezent, laserii sunt utilizate pentru debridare radiculară şi periodontală, în chirurgia periimplantară şi în terapia parodontală (13).

Chirurgia laser se poate efectua fără anestezie sau doar sub anestezie topică în unele cazuri (14). Laserii îşi găsesc aplicaţii în proceduri precum: frenectomia, gingivectomia, gingivoplastia, îndepărtarea țesutului de granulație, descoperirea implanturilor, ablația leziunilor, biopsia incizională şi excizională a leziunilor benigne sau maligne, iradierea ulcerelor aftoase, coagularea situsului donor gingival, depigmentare gingivală (15).

Extracția dentară atraumatică are un rol major în conservarea osului pacientului, pentru a putea obține o bună stabilitate primară a implantului.

Unii autori contraindică realizarea unui lambou cu scopul de a menține vascularizația periostului 
tablei osoase vestibulare (16). Totuşi, un lambou de amplitudine mică poate fi de ajutor, el permițând o bună vizualizare a câmpului operator şi reducerea timpului intervenției, estimarea cu precizie a dimensiunii tablei osoase în funcție de nivelul la care se găseşte în regiunea dintelui vecin, precum şi vizualizarea axei de implantare.

Forajul este adaptat în funcție de alveolă şi de calibrul implantului (diametru/lungime). Implantul este apoi plasat prin ghidajul apico-palatinal descris de Hwang, pentru ca în final implantul să fie poziționat palatinal în alveolă (16).

Sunt situații clinice când avem nevoie de augumentare osoasă prin intermediul unei xenogrefe şi al unei membrabe de colagen pentru a ghida cicatrizarea şi a obține o bună regenerare tisulară (16). Formarea cheagului permite umplerea alveolei şi are rol în apariția țesutului de neoformare necesar pentru a obține o bună stabilitate secundară.

În finalul intervenției, prin tracțiunea lejeră a lamboului, situsul operator este închis etanş prin suturarea plăgii, iar biostimularea efectuată cu laserul diodă are rolul de a îmbunătăți cicatrizarea postoperatorie şi a reduce durerea şi posibilul disconfort.

\section{CONCLUZII}

Utilizarea softului SimPlant ${ }^{\circledR}$ pentru planificarea tratamentului a crescut precizia actului operator.

Extracțiile dentare s-au realizat atraumatic pentru a proteja pe cât posibil osul restant al pacientului.

Decontaminarea locală parodontală şi decontaminarea osoasă laser asistată au avut rol în prevenirea apariției unor reacții inflamatorii sau infecțioase postimplantare.

Utilizarea implantelor Zimmer TSV ne-a ajutat să obținem o bună stabilitate primară şi o foarte bună stabilitate secundară.

Pacienta nu a prezentat complicații de natură inflamatorie sau infecțioasă la nici un control postoperator.

Limitele aplicabilității procedurii sunt date de costul crescut al aparaturii necesare şi de posibilele efecte nedorite ale iradierii laser impropriu efectuate de către specialişti insuficient pregătiți în domeniu.

Conflict of interest: none declared Financial support: none declared

\section{BIBLIOGRAFIE}

1. Leclercq P., Granjon O., Phillips D. Avulsion et implantation immediate, Actual. Odonto-Stomatol. 261:4-10, 2013.

2. Chen S.T., Darby I.B., Reynolds E.C. et al. Immediate implant placament postextraction without flap elevation, J. Periodontol, nr. 80(1), pag.163-172, 2009.

3. Gupta S., Patil N., Solanki J. et al. Oral implant imaging: A review, Malays J Med SCi, May-Jun 2015, 22 (3): 7-17, pag. 7-17.

4. Jacobs R., Quirynen M. Dental cone beam computed tomography: justification for use in planning oral implant placement. Periodontol 2000, 2014; 66:203-213.

5. Pozzi A., Pollizi G., May P.K. Guided surgery with toothsupported templates for single missing teeth: A critical review, Eur J Oral Implantol 2016, 9(Suppl 1): S135-S153.

6. Norkin F.J., Ganeles J., Zfaz S. et al. Assessing imageguided implant surgery în today's clinical practice, Compendium, 2013, p. 747-750.

7. Kochhar A., Ahuja S. Computer guided implantology: for optimal implant planning, Dent Implants Dentures: 2015; $1: 101$.

8. Lee J.H., Park J.M., Kim S.M. et al. An assessment of template-guided implant surgery in terms of accuracy and related factors, J Adv Prosthodont, 2013, 5: 440-447.

9. Bordea R., Lucaciu O., Câmpian R.S. Student's knowledge and opinion regarding the need of implementation of Lasers in Dental Faculty Curriculum, HVM Bioflux, vol 8, issue 4, 2016, pg. 157-160.

10. Dansie C.O., Park J.H., Makin I.R.S. Training and Use of Lasers în Postgraduate Orthodontic Programs in the United States and Canada. J Dent Educ 2013;77 (6): 773-81.

11. Verma S.K., Maheshwari S., Singh R.K. et al. Laser in dentistry:An innovative tool in modern dental practice. Natl J Maxillofac Surg 2012; 3(2):124-32.

12. Bhandari R., Singla K., Sandhu S.V. et al. Soft tissue applications of lasers: A review. Int J Dent Res 2014; 2(1):16-19.

13. Prabha C., Shreshtha S.M. An insight into Laser în periodontics: A review, International Journal of Community Health and Medical Research Vol. 3 Issue 1, 2017, p. 59-65.

14. Henry C.A., Judy M., Dyer B. et al. Sensitivity of Porphyromonas and Prevotella species in liquid media to argon laser. Photochem Photobiol, 1995: 61: 410-413.

15. Cobb C.M. Lasers în Periodontics. A Review of literature. J. Periodontal, 2006:77; 545-564

16. Hwang K.G., Park C.J. Ideal implant positioning in an anterior maxillary extraction socket by creating an apicopalatal guiding slot: a tehnical note, Int. J. Oral Maxillofac Implants, nr. 23 (1), pag.121-2, 2008. 